Abstract 424 Table 1 CVE in women with SLE born in Sweden between 1951-1971.

\begin{tabular}{|l|c|c|c|}
\hline & $\begin{array}{c}\text { Non-parous } \\
(n=915)\end{array}$ & $\begin{array}{c}\text { Preterm<34/40 } \\
(n=194)\end{array}$ & $\begin{array}{c}\text { Delivery } \geq 34 / 40 \\
(n=2,119)\end{array}$ \\
\hline CVE, $n$ (\%) & $138(15.1)$ & $30(15.5)$ & $166(7.9)$ \\
\hline Age at 1 st CVE, years (IQR) & $41(33-48)$ & $40.5(31-48)$ & $46(40-51)$ \\
\hline Incidence, per 1,000 person-years (95\% Cl) & $3.44(2.91-4.07)$ & $3.53(2.47-5.05)$ & $1.75(1.50-2.03)$ \\
\hline Adjusted hazard of a CVE, adjHR* (95\% Cl) & $1.42(1.14-1.78)$ & $1.22(1.09-1.37)$ & 1.0 \\
\hline Cl-confidence interval; * adjusted for CV risk factors and SLE-related morbidity. & \\
\hline
\end{tabular}

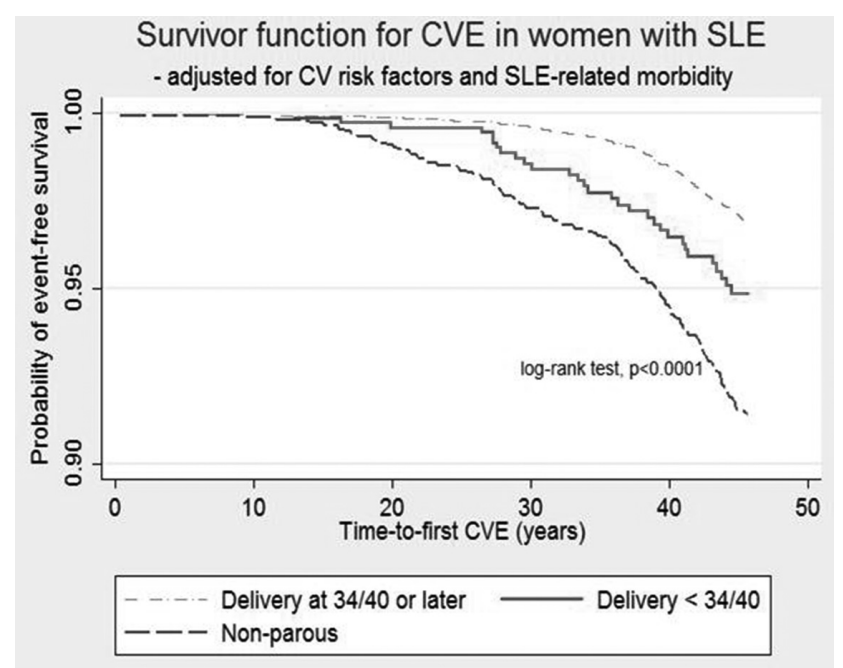

Abstract 424 Figure 1

$52 \%$ respectively, $\mathrm{p}=0.044$ ) (Figure 1 ). LN diagnosed in 1998-2013 was associated with 5 year and 10 year relapsefree survival rates of $93 \%$ and $86 \%$ respectively, compared with $81 \%$ and $66 \%$ respectively $(\mathrm{p}=0.017)$ for patients who presented in 1983-1997 (Figure 2).

Conclusions The risk of renal relapse has decreased in the current era, probably attributed to replacement of AZA with MPA as maintenance treatment.

\section{PRE-EMPTIVE TREATMENT FOR ASYMPTOMATIC SEROLOGICAL REACTIVATION IN LUPUS NEPHRITIS PATIENTS - IMPACT ON CLINICAL FLARE RATE AND RENAL FUNCTION}

DYH Yap*, MK Ma, MM Mok, GC Chan, LP Kwan, TM Chan. Queen Mary Hospital- The University of Hong Kong, Department of Medicine, Hong Kong, Hong Kong S.A.R

10.1136/lupus-2017-000215.428
Background and aims Pre-emptive immunosuppressive treatment for asymptomatic serological activation (ASR) in lupus nephritis (LN) patients remains controversial, and its impact on subsequent flare rate and long-term renal outcome is unclear.

Methods We conducted a retrospective study on all episodes of ASR in 1993-2015 to investigate the relationship between pre-emptive treatment and subsequent clinical flares and renal outcomes.

Results 138 episodes of ASR occurred in 98 patients during the study period. 53 episodes (in 38 patients) were treated with pre-emptive increase in immunosuppression while 85 episodes (in 60 patients) were not, and patients were followed up for $88.8 \pm 77.3$ months and $82.8 \pm 89.7$ months respectively after ASR occurred. Pre-emptive treatment was associated with superior renal relapse-free survival $(100 \%, 95 \%$ and $90 \%$ at 6, 12 and 24 months respectively) compared with no preemptive treatment (93\%, 68\% and 65\% respectively, $\mathrm{p}=0.007)$, while extra-renal relapse-free survival did not differ between the two groups (Figure 1). 5 (9.4\%) of 53 ASR episodes treated pre-emptively developed renal flare at $14.3 \pm 6.7$ months after ASR. Patients who received pre-emptive treatment for ASR and did not develop renal flares showed also better eGFR slope $\left(+0.54 \pm 0.43 \mathrm{ml} / \mathrm{min} / 1.73 \mathrm{~m}^{2} /\right.$ year $)$ compared with the non-pre-emptive groups with or without renal flares $\left(-2.11 \pm 0.50\right.$ and $-1.00 \pm 0.33 \mathrm{ml} / \mathrm{min} / 1.73 \mathrm{~m}^{2} /$ year respectively, $\mathrm{p}=0.001$ and 0.012 ) (Figure 2). Pre-emptive treatment was associated with more gastrointestinal adverse events related to increased mycophenolate dose $(p=0.031)$. Infection rate was similar between both groups.

Conclusions Renal flares have a negative impact on renal function and pre-emptive treatment for ASR could reduce renal flare risk and its consequences in LN patients.

\section{ANTIPHOSPHOLIPID ANTIBODY POSITIVITY AND RELATED CLINICAL CHARACTERISTICS IN KOREAN LUPUS PATIENTS}

${ }^{1} \mathrm{~S}$ Nam, ${ }^{1} \mathrm{D} \mathrm{Kim} *,{ }^{1} \mathrm{SK}$ Cho, ${ }^{2} \mathrm{KE}$ Lee, ${ }^{2} \mathrm{DJ}$ Park, ${ }^{2} \mathrm{SS}$ Lee, ${ }^{1}$ YK Sung. ${ }^{1}$ Hanyang University Hospital for Rheumatic Diseases, Rheumatology, Seoul, Republic of Korea; ${ }^{2}$ Chonnam national university medical school and hospital, Rheumatology, Gwangju, Republic of Korea

10.1136/lupus-2017-000215.429 


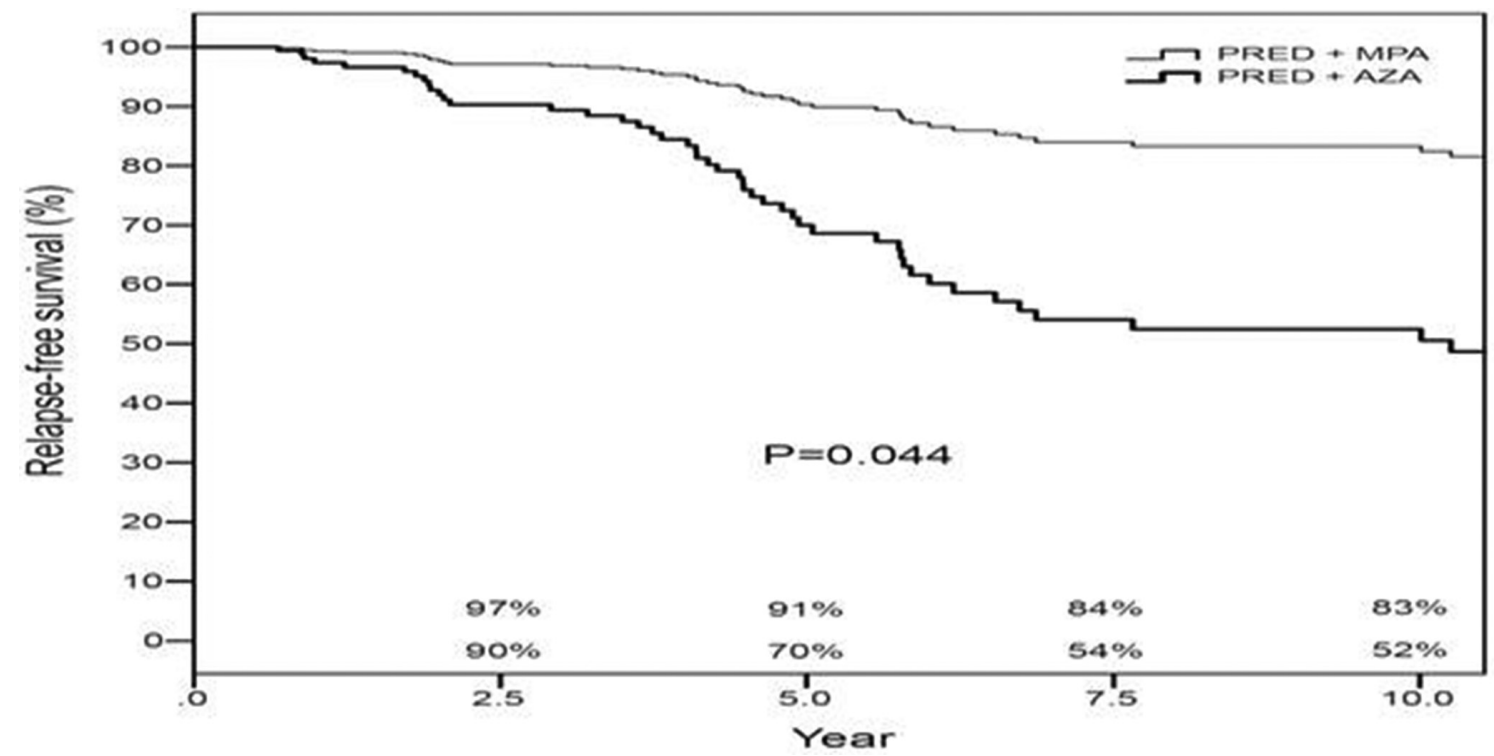

Abstract 427 Figure 1

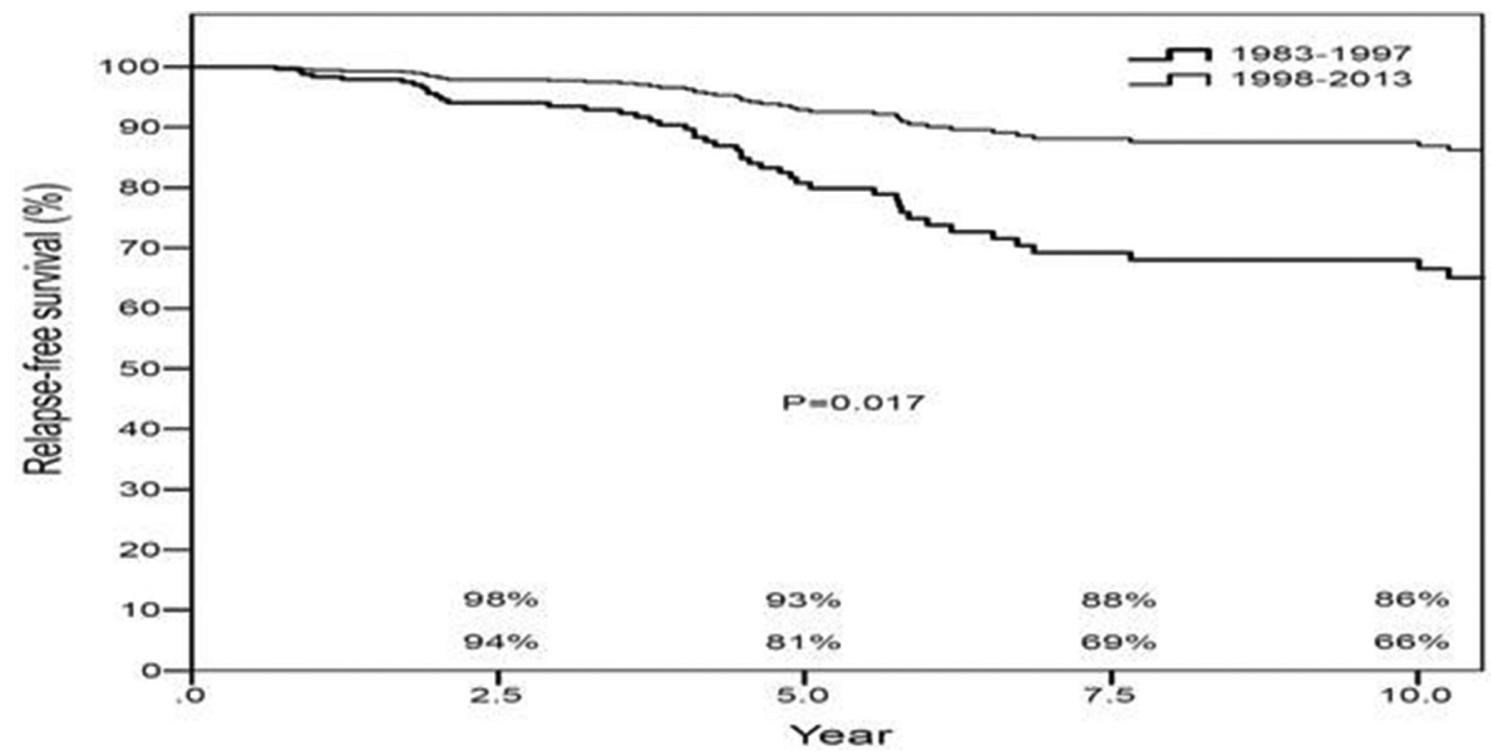

Abstract 427 Figure 2

Background and aims To identify the prevalence of positive antiphospholipid antibodies (aPL) and related clinical characteristics in Korean SLE patients

Methods Among 505 SLE patients from KORean lupus NETwork (KORNET), we selected 469 patients who underwent aPL tests within 2 years of enrollment. They were classified into two groups: 1) aPL (+) group as patients with at least one positive aPL which includes IgG anticardiolipin antibody (aCL > $40 \mathrm{GPLU} / \mathrm{ml}$ ), IgG anti-ß2 glycoprotein I (anti- ß2GPI $>40 \mathrm{SGU} / \mathrm{ml}$ ) and lupus anticoagulant (LAC), and 2) aPL (-) groups as patients with negative aPL. We compared the demographic and clinical characteristics between two groups, and clinical symptoms of thrombosis and obstetric complications were compared according to aPL positivity.
Results The 49 (10.4\%) SLE patient had at least one positive aPL, and all 3 aPL were positive in 1 patient $(0.2 \%)$. Although age, sex, autoantibody profile, and the SELENA SLEDAI score were not different between two groups, the SLICC/ACR damage index was higher in aPL $(+)$ group $(p=0.03)$, and $57.1 \%$ of aPL $(+)$ patients were using aspirin. More patients in aPL $(+)$ group underwent cerebrovascular disease (CVD) $(<0.01)$, whereas no statistical difference was found in history of ischaemic heart disease or spontaneous abortion. Moreover, renal failure was higher in aPL (+) group $(p<0.01)$, while lupus nephritis was comparable between two groups $(\mathrm{p}=0.70)$. 

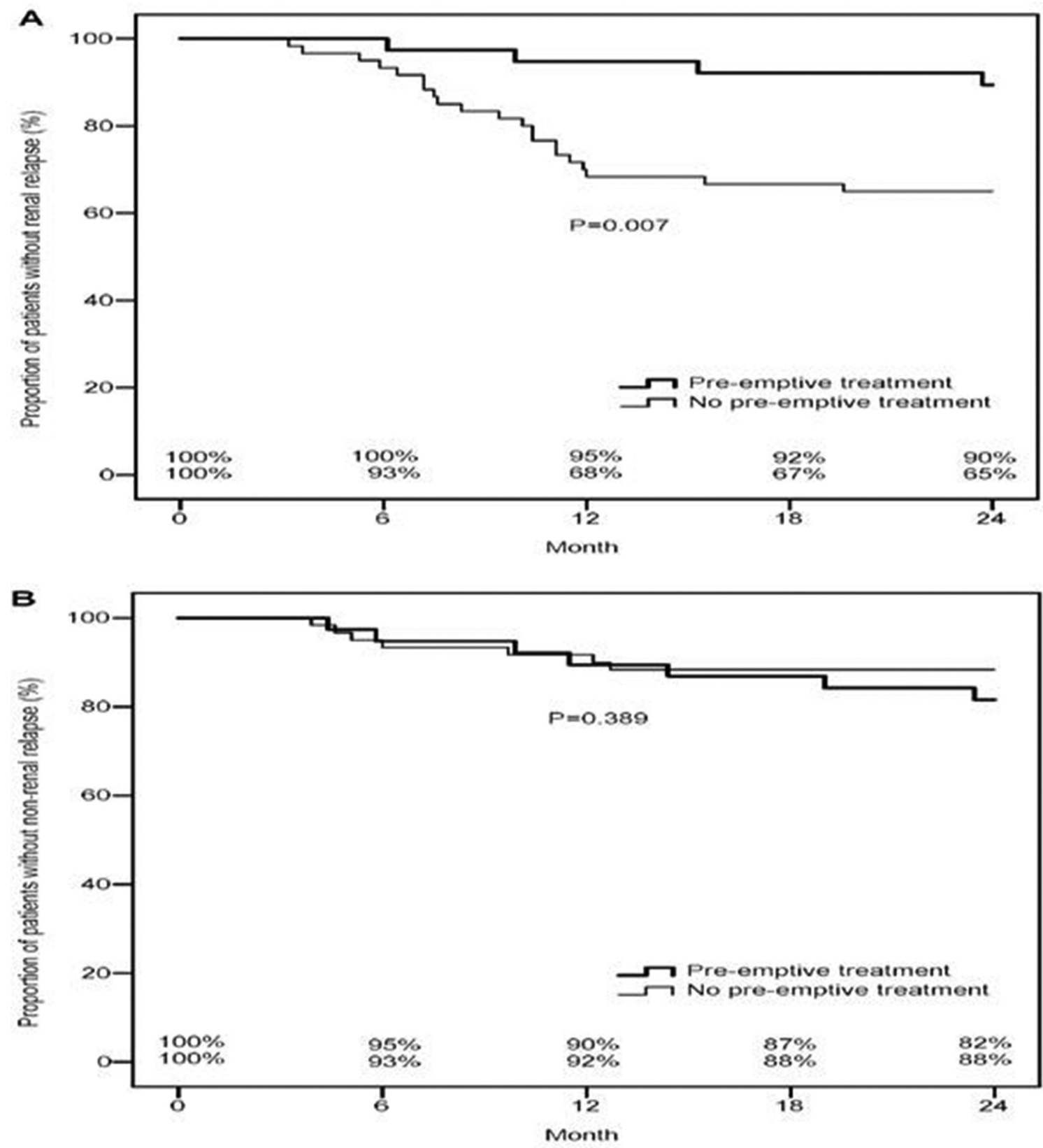

\section{Abstract 428 Figure 1}

Conclusions Ten percent of patients had positive aPL in Korean SLE patients. In addition, CVD and renal failure were more common in patients with aPL (+) SLE patients.

\section{RISK FACTORS FOR HERPES ZOSTER INFECTION AMONG FILIPINOS WITH SYSTEMIC LUPUS ERYTHEMATOSUS: A CASE CONTROL STUDY}

L Zamora*, S Leynes, S Navarra. University of Santo Tomas Hospital, Section of Rheumatology, Manila, Philippines

\subsection{6/lupus-2017-000215.430}

Background and aims Herpes-zoster (HZ) has higher occurrence in systemic lupus erythematosus (SLE) compared to the general population. This study aimed to identify risk factors associated with $\mathrm{HZ}$ infections in SLE.

Methods We included patients from Lupus Database of University of Santo Tomas (UST) Hospital, Manila, Philippines, who were diagnosed with $\mathrm{HZ}$ infection. Controls included SLE patients without $\mathrm{HZ}$ matched for age, sex and disease duration. SLE disease activity, corticosteroid, immunosuppressives, and hydroxychloroquine were compared between groups.

Results In a review of 626 patient records, 65 SLE patients (61, 93.8\% females) developed HZ, with incidence 10.4/1000 person-years. Mean age was 36.5 years+11 (range 19-60), mean SLE disease duration to $\mathrm{HZ} 6.1$ years+3.3 (range 217). HZ lesions were localised in $63(97 \%)$, disseminated in 2 (3\%) patients. Four patients had $>2 \mathrm{HZ}$ episodes. All responded favourably to anti-viral therapy with minimal 